\title{
Glutamate Receptors in the Nucleus Accumbens Shell Control Feeding Behavior via the Lateral Hypothalamus
}

\author{
Carmen S. Maldonado-Irizarry, ${ }^{1}$ Chad J. Swanson, ${ }^{2}$ and Ann E. Kelley ${ }^{2}$ \\ 'Department of Psychology, Northeastern University, Boston, Massachusetts 02114 and ${ }^{2}$ University of Wisconsin- \\ Madison Medical School, Department of Psychiatry, Madison, Wisconsin 53705
}

The nucleus accumbens is a brain region considered to be important in the regulation of appetitive behavior and reinforcement. The accumbens receives afferent input from corticolimbic and thalamic structures, which is primarily coded by excitatory amino acids (EAAs). The present studles Investigated the role of EAA Input to the nucleus accumbens in feeding behavior in rats, in two recently characterized subregions of the accumbens, the "core" and "shell." In the first series of experiments, it was shown that blockade of $\alpha$-amino-3-hydroxy-5-methylisoxazole-4-propionic acid (AMPA) and kainate glutamate receptors in the medial part of the accumbens, corresponding to the medial shell subregion, resulted in a pronounced feeding response. Bilateral microinfusion of 6,7-dinitroquinoxaline2,3-dione (DNQX, 0.25-0.75 $\mu \mathrm{g} / 0.5 \mu \mathrm{l}$ ), 6-cyano-7-nitroquinoxaline (CNQX, 0.75-1.5 $\mu \mathrm{g}$ ), and 2,3-dihydroxy-6-nitro-7sulfamoylbenzo-(F) quinoxaline (NBQX, 0.2-1.0 $\mu \mathrm{g}$ ) markedly stimulated food intake immediately following infusion, in a dose-dependent manner. Infusion of DNQX into the central accumbens region, corresponding to the core, did not elicit feeding. Infusion of the NMDA antagonists 2-amino-5-phosphonopentanoic acld (AP-5) and MK-801 (dizocilpine maleate) did not elicit feeding in either region. The feeding response to DNQX was blocked by local coinfusion of AMPA. Systemic pretreatment with naltrexone $(5 \mathrm{mg} / \mathrm{kg}$ ) had no effect on the DNQX-feeding response; however, prior systemic administration of both D-1 and D-2 antagonists reduced the response by half, suggesting a modulatory role for dopamine in the response. Moreover, the feeding response was completely inhibited by concurrent infusion of the GABA agonist muscimol $(10,25 \mathrm{ng})$ into the lateral hypothalamus, a major projection area of the accumbens shell. These findings demonstrate a selective role for nonNMDA receptors in the nucleus accumbens shell in ingestive behavior, and suggest an important functional link between two major brain regions involved in reward, the nucleus accumbens and lateral hypothalamus.

[Key words: nucleus accumbens, glutamate, excitatory amino acids, striatum, feeding behavior, motivation]

\footnotetext{
Received Feb. 28, 1995; revised June 12, 1995; accepted June 14, 1995.

We acknowledge support from the National Institute on Drug Abuse (Grant DA04788). C.S.M.-I. was supported by the American Psychological Association Minority Fellowship Program. We thank Dr. Leonard Levin for criticism of the manuscript.

Correspondence should be addressed to Dr. Ann E. Kelley, Department of Psychiatry, 2671 Medical Sciences Center, 1300 University Avenue, Madison, WI 53705 .

Copyright (c) 1995 Society for Neuroscience $0270-6474 / 95 / 156779-10 \$ 05.00 / 0$
}

The nucleus accumbens, located within the ventromedial striatum, is a critical neural substrate for reinforcement processes and appetitive behavior. Empirical findings implicate this structure in the rewarding and euphoriant effects of drugs of abuse, such as psychostimulant drugs, opiates and alcohol (Wise and Bozarth, 1987; Koob and Bloom, 1988; Weiss et al., 1993). Moreover, a common theme of many psychological theories pertaining to the nucleus accumbens, and in particular to its dopaminergic innervation, is that this neural system plays a key role in instrumental behavior elicited by incentive (reward-related) stimuli (Beninger, 1983; Fibiger and Phillips, 1986; Robbins et al., 1989). The anatomical organization of the nucleus accumbens is well-suited to this role. Within this area there is a convergence of information related to affective and motivational states, arising from limbic structures such as amygdala, hippocampus, prefrontal cortex, and brainstem autonomic centers (Heimer and Wilson, 1975; Kelley et al., 1982; Groenewegen and Russchen, 1984). Further, it has extensive connections to motor output systems (Groenewegen et al., 1980). Thus, the nucleus accumbens has been viewed as an interface between the corticolimbic and motor systems, where processing of affective information is translated into motor actions (Mogenson et al., 1980).

Although the nucleus accumbens has long been considered a ventral striatal territory with prominent similarities to the overlying caudate-putamen, in recent years there has been a major anatomical re-conceptualization of this structure. Analysis of connectivity as well as its histochemical profile indicates that the nucleus accumbens is composed of three major subterritories, which have been termed the core, shell, and rostral pole. The core and shell subregions, which have been most extensively studied, show striking differences in their efferent projections (Heimer et al., 1991; Zahm and Brog, 1992; Brog et al., 1993). The core subregion connects extensively to classic basal ganglia output structures, such as the ventral pallidum, subthalamic nucleus, and substantia nigra. The shell subregion, in contrast, projects most heavily to subcortical limbic regions, such as the lateral hypothalamus and ventral tegmental area. On the basis of these distinctive anatomical profiles, it has been proposed that there may be significant functional specializations of these two subregions and their associated circuitry (Alheid and Heimer, 1988; Deutch and Cameron, 1992; Deutch et al., 1993).

Our studies were conducted utilizing local microintusions of excitatory amino acid (EAA) antagonists. The majority of corticolimbic inputs to the striatum and nucleus accumbens utilize EAAs as their neurotransmitter, and high concentrations of all subtypes of EAA receptors are found in the accumbens (McGeert et al., 1977; Walaas and Fonnum, 1979; Fuller et al., 1987; 
Robinson and Beart, 1988; Albin et al., 1992). Moreover, a substantial proportion of all subtypes of EAA receptors within the striatum, including AMPA, kainate, and NMDA receptors, have been demonstrated to be localized on striatonigral output neurons (Tallaksen-Green et al., 1992). A number of studies utilizing intra-accumbens injections of EAA antagonists have suggested that these receptors play in important role in behavior and in dopaminergic regulation. For example, pretreatment of the accumbens with NMDA or non-NMDA antagonists reduces the locomotor and rewarding effects of psychostimulant drugs (Kelley and Throne, 1992; Pulvirenti et al., 1992; Kaddis et al., 1993; Burns et al., 1994), and accumbens infusion of NMDA antagonists disrupts exploratory and spatial behavior (Schacter et al., 1989; Maldonado and Kelley, 1994, 1995).

As part of a project evaluating the behavioral effects of blockade of excitatory amino acid receptors in the nucleus accumbens, we made the serendipitous observation that animals that had been injected with 6,7-dinitroquinoxaline-2,3-dione (DNQX), which blocks both AMPA and kainate receptors, exhibited pronounced feeding when placed back in their home cage. Only animals injected into a medial accumbens region, corresponding to the medial shell, showed this effect. A series of experiments was then conducted that examined this phenomenon in detail. We report here complete behavioral dissociation between these two regions, as well as evidence of a functional pathway between accumbens shell and lateral hypothalamus.

\section{Materials and Methods}

Animals and surgery. A total of sixty-nine male Sprague-Dawley rats (Harlan Sprague-Dawley, Wisconsin) were maintained with food and water ad libitum throughout the experiments. Animals were housed in groups and were handled daily to minimize stress. Care of animals was in accordance with institutional guidelines. For implantation of chronic indwelling guide cannulae (23 gauge), animals were anesthetized with sodium pentobarbital $(50 \mathrm{mg} / \mathrm{kg}$, i.p.). Standard stereotaxic procedures, described in detail elsewhere (Maldonado-Irizzarry and Kelley, 1994), were used. (It should be noted that the core and shell subregions cannot easily be distinguished in Nissl-stained sections; placements referred to as "central" and "medial" are meant to approximate the areas designated as "core" and "shell" in immunohistochemically stained material). Coordinates for the medial accumbens placement were (in $\mathrm{mm}$, with toothbar $5.0 \mathrm{~mm}$ above interaural zero): A-P, +3.5 from bregma; $\mathrm{M}-\mathrm{L}, \pm 1.1$ from midline; $\mathrm{D}-\mathrm{V},-5.3$ from skull surface. Coordinates for the central accumbens placement were: A-P, $+3.5 ; \mathrm{M}-\mathrm{L}, \pm 1.8$; and $\mathrm{D}-\mathrm{V},-5.3$. In one experiment two sets of bilateral cannulae were implanted aimed at the medial accumbens and the lateral hypothalamus $(\mathrm{LH})$ in the same rats. The coordinates for the $\mathrm{LH}$ were: A-P, 0 from bregma; $M-L, \pm 2.0$ from midline; and $D-V,-6.2$ from skull. A recovery period of several days was allowed before behavioral testing.

Drugs and microinfusion. DNQX, 6-cyano-7-nitroquinoxaline-2,3-dione (CNQX), 2-amino-5-phosphonopentanoic acid (AP-5), MK-801 (dizocilpine maleate), AMPA, muscimol, naltrexone, and SCH 23390 were obtained from Research Biochemicals International, Natick, MA. 2,3Dihydroxy-6-nitro-7-sulfamoyl-benzo (f) quinoxaline (NBQX) was obtained from Tocris Neuramin, Bristol, England. Haloperidol (injectable form) was obtained from LyphoMed, Rosemont, IL. DNQX, CNQX, and NBQX were dissolved in a $50 \%$ solution of dimethylsulfoxide (DMSO) and distilled water. The vehicle for the non-NMDA antagonists was 50\% DMSO and distilled water. All other drugs were dissolved in isotonic sterile saline. Intracerebral (i.c.) microinfusions were always bilateral in a volume of $0.5 \mu \mathrm{l}$. After removal of the occluding stylets, infusions of drug or vehicle were given by lowering a 30 gauge injector cannulae to the site of infusion ( -7.8 from skull for $N$. Acc., -8.7 for the LH). A microdrive pump (Harvard Apparatus) was used to administer drug infusions to the site with an infusion time of 1 min $33 \mathrm{sec}$ followed by $1 \mathrm{~min}$ of diffusion time. After this step, the injectors were removed, the stylets were replaced and the animals were tested, beginning $5 \mathrm{~min}$ following the end of infusion.

Experimental design. In the first experiment, there were two groups of rats implanted with cannulae aimed at either the medial accumbens (shell group, $n=7$ ) or the central accumbens (core group, $n=11$ ), that each received DNQX (shell group, $0,0.25,0.75 \mu \mathrm{g}$; core group, $0,0.75 \mu \mathrm{g})$. In the second experiment, two groups implanted in the medial accumbens were infused with either $\operatorname{NBQX}(n=9 ; 0,0.2,1.0$ $\mu \mathrm{g})$, or CNQX $(n=6 ; 0,0.75,1.5 \mu \mathrm{g})$. Three further groups of rats were treated with AP-5 in the medial accumbens $(n=6 ; 0,0.2,1.0$ $\mu \mathrm{g}), \mathrm{AP}-5$ in the central accumbens $(n=6 ; 0,0.2,1.0 \mu \mathrm{g})$ or MK-801 in the medial accumbens $(n=7 ; 0,1.0 \mu \mathrm{g})$. In a third experiment, a group $(n=4)$ was implanted with a unilateral cannulae at an angle of $2.5^{\circ}$ so as to avoid penetration of the ventricle, and injected with DNQX $(0.75 \mu \mathrm{g})$. In the fourth experiment, a group of rats $(n=6)$ was implanted in the medial accumbens and given either AMPA $(1 \mu \mathrm{g})$ or AMPA plus DNQX $(0.75 \mu \mathrm{g})$. In the fifth experiment, a group of rats $(n=7)$ implanted in the medial accumbens and given DNQX $(0.75$ $\mu \mathrm{g}$ ) in combination with various systcmic treatments: i.p saline, SCH$23390(0.1 \mathrm{mg} / \mathrm{kg})$, haloperidol $(0.25 \mathrm{mg} / \mathrm{kg})$, or naltrexone $(5 \mathrm{mg} / \mathrm{kg})$. In the last experiment, a group of rats was implanted with cannulae in both the medial accumbens and lateral hypothalamus $(n=6)$. These rats were infused with combinations of DNQX $(0.75 \mu \mathrm{g})$ or vehicle in the accumbens, and muscimol $(0,10,25 \mathrm{ng})$ or vehicle in the lateral hypothalamus. All experiments utilized a within-subjects design such that for each group, each animal received all doses or treatments. All drug treatments were administered in a counterbalanced order, with at least $2 \mathrm{~d}$ between each injection. For all experiments except that with systemic injections, animals never received more than three i.c. injections. For the experiments with systemic injections, animals received a total of four i.c. injections. In that experiment, naltrexone was administered $15 \mathrm{~min}$ prior to i.c. infusions, and DA antagonists were administered $30 \mathrm{~min}$ prior to i.c. infusions.

Behavioral testing and data analysis. Prior to behavioral testing, rats were adapted to handling and to the testing room and cages. On the test day, a premeasured amount of food was placed in the test cage, and a paper was placed beneath the cage in order to measure food spillage. Water was available at all times. During a $30 \mathrm{~min}$ observation period following microinfusion, feeding behavior was recorded by an observer blind to treatment, with an electronic counter interfaced to a microcomputer (Paul Fray Ltd., Cambridge, England). Behavioral parameters recorded were feeding duration and bouts, drinking duration and bouts, latency to feed and drink, locomotion (crossings over the midline of the cage), and rearing. At the end of each test session, total food intake (grams) was calculated. All data were analyzed by multifactorial analysis of variance, with repeated measures and posthoc contrasts where appropriate.

Histology. Following the completion of experiments, animals were overdosed with sodium pentobarbital and perfused transcardially with saline following by $10 \%$ formalin. The brains were removed and stored in $10 \%$ sucrose formalin solution for several days before sectioning. For histological preparation, brains were cut into $60 \mu \mathrm{m}$ sections, mounted, and stained with cresyl violet. Sections were then examined under a light microscope for verification of cannula placement and assessment of the injection site. Animals that did not have both cannula tips clearly in either the central or medial nucleus accumbens were excluded from analysis. Some sections were photographed; drawn reconstructions of injection sites were also made.

\section{Results}

\section{Effect of EAA antagonists on feeding}

In the group with cannulae aimed at the medial accumbens (corresponding to the shell subregion), DNQX induced robust, dosedependent feeding that was immediate in onset and long-lasting (Fig. 1 and Table 1). There was a significant dose effect for food intake $[F(2,12)=35.1, p<0.001]$; both doses significantly increased food intake above baseline. When placed back in the test cage at the end of the microinfusion, animals went immediately to a food pellet and began feeding. Feeding behavior was nearly constant in the first ten minutes and gradually subsided towards the end of the test session. For feeding duration, a significant dose effect $[F(2,12)=7.1, p<0.01]$ and dose $\times$ time interaction $[F(4,24)=4.18, p<0.01]$ was found. Post-hoc analysis (simple main effects) of feeding duration scores revealed this interaction to be due to differences between both 

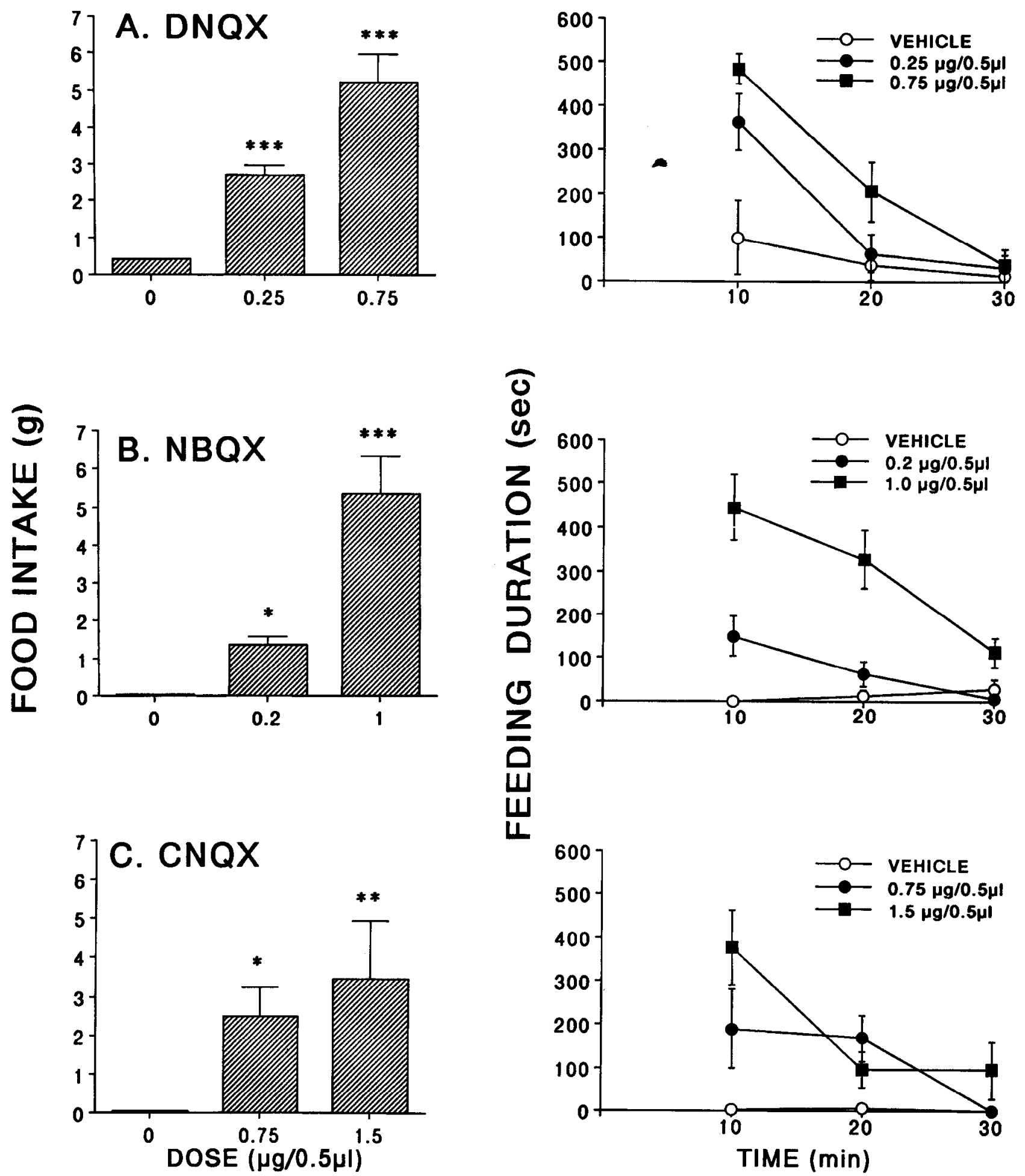

Figure 1. Food intake and feeding duration scores following infusion of non-NMDA antagonists into the medial nucleus accumbens, corresponding to the medial shell subregion. $A$, Effects of DNQX $(n=7) ; B$, Effects of NBQX $(n=9) ; C$, Effects of CNQX $(n=6)$. *, $p<0.05 ; * *, p<$ $0.01 ; * * *, p<0.001$ (for complete statistical analysis, see Results).

dose groups and vehicle. General motor activity followed a pattern that was inverse to feeding; activity levels were low in the initial part of the test session, when animals were constantly feeding, and became higher toward the end of the session, when some animals ceased feeding. [For example, the locomotor activity scores (means $\pm S E M$ ) at the 10,20 , and 30 min time points were, following DNQX injection into medial accumbens (high dose): $8 \pm 2,30 \pm 10,41 \pm 10$, respectively; following vehicle injection they were $17 \pm 3,6 \pm 2,2 \pm 1$; significant interaction, $F(2,24)=13.9, p<0.001$.] In contrast, DNQX injections into the central accumbens, corresponding to the core subregion, did not significantly affect feeding (Table 2). 


\begin{tabular}{lc}
\hline $\begin{array}{l}\text { Table 1. Effect of EAA antagonists infused into the medial } \\
\text { accumbens on latency to eat }\end{array}$ \\
$\begin{array}{l}\text { Latency to eat } \\
\text { Treatment }\end{array}$ \\
$(\mu \mathrm{g} / 0.5 \mu \mathrm{s})$ \\
\hline DNQX, medial accumbens \\
0 & 416.7 \\
0.25 & 100.7 \\
0.75 & 20 \\
NBQX, medial accumbens & \\
0 & $*$ \\
0.2 & 49.3 \\
1.0 & 9.6 \\
CNQX, medial accumbens & 893.3 \\
0 & 362.6 \\
0.75 & 9 \\
1.5 & \\
DNQX, medial accumbens, & \\
+ AMPA $(n=6)$ & $*$ \\
AMPA $(1 \mu \mathrm{g})+$ saline & 804.4 \\
AMPA $(1 \mu \mathrm{g})+$ DNQX $(0.75 \mu \mathrm{g})$ & \\
DNQX, medial accumbens, + muscimol, LH & \\
DNQX $(0.75 \mu \mathrm{g})+$ saline & 4.9 \\
DNQX $+10 \mathrm{ng}$ muscimol & \\
DNQX $+25 \mathrm{ng}$ muscimol & \\
\hline
\end{tabular}

Values in the latency column represent the median latency. An asterisk in the place of a latency score indicates that no animals fed in that treatment group. Total duration of test session was $1800 \mathrm{sec}$.
In order to test the pharmacological specificity of this behavioral effect, several further experiments were carried out. In new groups of animals, two further compounds selective for blocking AMPA and kainate receptors, NBQX and CNQX, were injected into the medial region of accumbens. Both these compounds induced a marked feeding response, reflected both in increased gram intake and feeding duration (Fig. 2), and extremely short feeding latencies (Table 1). NBQX induced a significant dose effect for food intake $[F(2,16)=40.5, p<0.001]$; posthoc contrast tests indicated that both the low and high dose contributed to this effect. For feeding duration, a significant dose effect $[F(2,16)=31.1, p<0.001]$ and dose $\times$ time interaction $[F(4$, $32)=5.5, p<0.01]$ were found. Analysis of simple main effects indicated this interaction to be due to a difference between the high dose group and vehicle $[F(2,32)=10.9, p<$ $0.01]$. CNQX induced a significant effect on food intake $[F(2$, 10) $=7.3, p<0.01$, with both doses significantly increasing intake. For feeding duration, a significant dose effect $[F(2,10)$ $=6.4, p<0.05]$ and significant dose $\times$ time interaction $[F(4$, 20) $-8.4, p<0.001]$ was found. This interaction was due to a difference between the high dose group and vehicle $[F(2,20)$ $=12.5, p<0.01]$.

Since there are high levels of NMDA receptors in the nucleus accumbens, it was also of interest to ascertain whether blockade of these receptors would also elicit feeding. The selective, competitive NMDA antagonist AP-5 did not elicit feeding in either the medial or central region (Table 2). Infusion of MK-801, a noncompetitive NMDA antagonist, also did not affect feeding when infused into the medial accumbens site.

Table 2. Effect of EAA antagonists infused into the nucleus accumbens on feeding parameters

\begin{tabular}{|c|c|c|c|}
\hline $\begin{array}{l}\text { Treatment } \\
(\mu \mathrm{g} / 0.5 \mu \mathrm{l})\end{array}$ & $\begin{array}{l}\text { Food intake } \\
(\mathrm{gm})\end{array}$ & $\begin{array}{l}\text { Feeding duration } \\
\text { (sec) }\end{array}$ & $\begin{array}{l}\text { Latency } \\
\text { to eat } \\
\text { (sec) }\end{array}$ \\
\hline \multicolumn{4}{|c|}{ DNQX, central accumbens $(n=11)$} \\
\hline 0 & $0.4 \pm 0.3$ & $12.2 \pm 7.9$ & $*$ \\
\hline 0.75 & $0.7 \pm 0.4$ & $119.7 \pm 82.4$ & 614.7 \\
\hline \multicolumn{4}{|l|}{ AP-5, central accumbens $(n=6)$} \\
\hline 0 & $0.06 \pm 0.05$ & $16.5 \pm 10.6$ & 817.2 \\
\hline 0.2 & $0.03 \pm 0.01$ & $*$ & * \\
\hline 1.0 & $0.02 \pm 0.02$ & $*$ & * \\
\hline \multicolumn{4}{|l|}{ AP-5, medial accumbens $(n=6)$} \\
\hline 0 & $0.1 \pm 0.1$ & $*$ & $*$ \\
\hline 0.2 & $0.08 \pm 0.1$ & $22 \pm 18.1$ & $*$ \\
\hline 1.0 & $0.01 \pm 0.0$ & $*$ & * \\
\hline \multicolumn{4}{|c|}{ MK-801, medial accumbens $(n=7)$} \\
\hline $\mathbf{0}$ & $0.05 \pm 0.4$ & $9.5 \pm 5.9$ & 686.2 \\
\hline 1.0 & $0.04 \pm 0.2$ & $1.4 \pm 0.9$ & * \\
\hline \multicolumn{4}{|c|}{$\begin{array}{l}\text { DNQX, medial accumbens }(n=7) \\
\quad+\text { systemic treatment (i.p.) }\end{array}$} \\
\hline DNQX $(0.75 \mu \mathrm{g})+$ saline & $5.5 \pm 0.7$ & $964.3 \pm 124.1$ & 6.9 \\
\hline + Naltrexone (5 mg/kg) & $5.0 \pm 1.0$ & $861.5 \pm 154.8$ & 7.1 \\
\hline + Haloperidol $(0.25 \mathrm{mg} / \mathrm{kg})$ & $2.0 \pm 1.1+\dagger \dagger$ & $486.7 \pm 205.3 \uparrow$ & 6.5 \\
\hline + SCH-23390 (0.1 mg/kg) & $2.8 \pm 0.7 \dagger \dagger \dagger$ & $442.3 \pm 126.5 \dagger$ & 5.3 \\
\hline
\end{tabular}

Values in latency column are medians; asterisk indicates no animals fed in that treatment group. $\uparrow \dagger \uparrow, p<0.001 ; \dagger$ $p<0.05$ (treatment effects compared with systemic saline condition). 


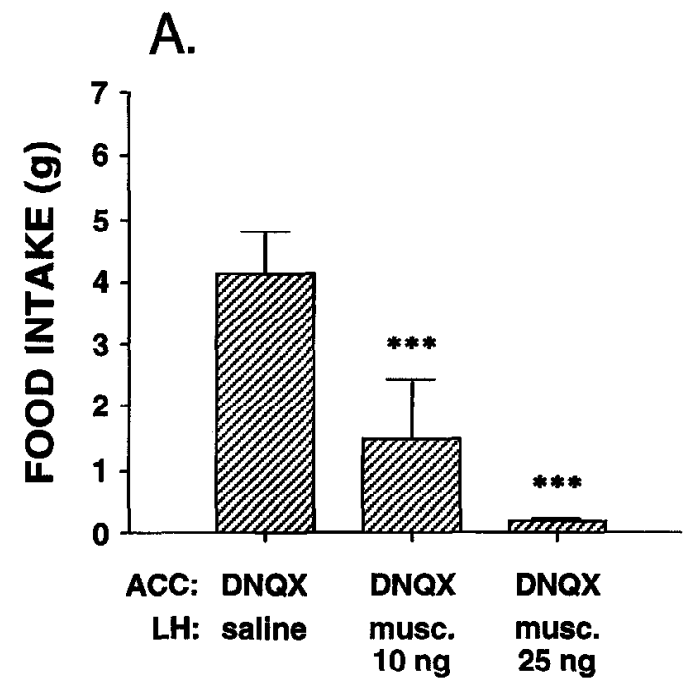

TREATMENT

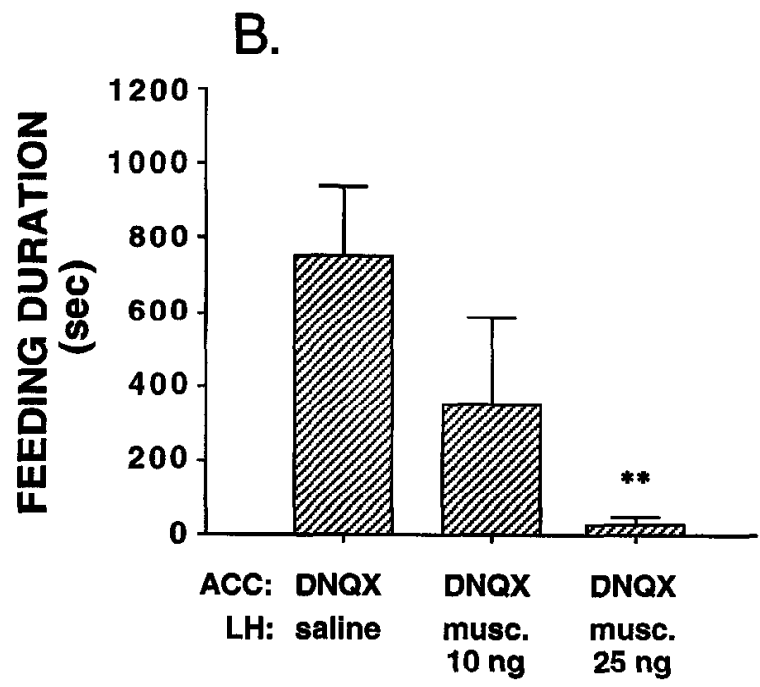

TREATMENT

Figure 2. Food intake (left side, $A$ ) and feeding duration (right side, B) following DNQX infusion into the medial nucleus accumbens, in combination with muscimol or vehicle infusion into the lateral hypothalmus $(n=6)$. There was a significant overall treatment effect for both food intake and feeding duration. ${ }^{* *}, p<0.01 ; * *, p<0.001$.

A further experiment was carried out as a control for diffusion to the lateral ventricle. Since the medial placement appears to sometimes penetrate the ventricle, it is possible that behavioral effects observed might be due to drug diffusion to the ventricle, and activity at a site other than the shell. An experiment was carried out in which animals had unilateral cannulae aimed at the medial shell, angled $2.5^{\circ}$ so as to avoid penetration of the ventricle (see Fig. 4). In these animals, a feeding response was also obtained following infusion of $0.75 \mu \mathrm{g}$ DNQX, although it was less than that normally observed following bilateral infusion. The mean intake following drug was $2.2 \pm 1.2 \mathrm{gm}$, and mean feeding duration was $265 \pm 13 \mathrm{sec}$. A $t$ test comparing these scores with those following unilateral saline infusion revealed statistical significance $(p<0.03)$.

\section{Role of various receptors in DNQX-induced feeding}

Several additional experiments evaluated the role of various receptors in the DNQX-induced feeding effect. First, the effect of DNQX was tested in the presence of AMPA, which would be expected to compete with DNQX and reduce its behavioral effects. In this experiment, AMPA was infused into the medial accumbens just prior to the DNQX infusion. In these animals, DNQX had no effect on feeding behavior (food intake for the AMPA + DNQX condition was 1.2 $\pm 0.7 \mathrm{gm}$ ); AMPA infused alone also did not affect feeding (Table 1). In the next experiment, the effects of prior systemic pretreatment with either opiate or dopamine antagonists were analyzed. It was reasoned that opiate receptors might bc involved, since high levcls of opiatc receptors are found in the shell of the accumbens, and since opiates are well known to enhance ingestive behavior (Mansour et al., 1987; Cooper and Kirkham, 1993). However, a dose of systemic naltrexone that could be expected to easily antagonize opiate-mediated effects $(5 \mathrm{mg} / \mathrm{kg}$ ) had no effect on DNQX-induced feeding (Table 2). Food intake, feeding duration, and median latencies to feed following DNQX infusions were similar in both naltrexone and saline-pretreated animals. Since dopaminergic receptors in the nucleus accumbens may play an important role in motivated behavior, the effects of prior treatment with a D-1 receptor antagonist (SCH-23390, $0.1 \mathrm{mg} / \mathrm{kg}$, i.p.) and a D-2 antagonist (haloperidol, $0.25 \mathrm{mg} / \mathrm{kg}$ ) were also tested. In contrast to naltrexone, the dopamine antagonists both significantly reduced the DNQX-induced feeding (Table 2). There was a significant overall effect of pretreatment on food intake $[F(2$, 16) $=18.93, p<0.001]$, due to effects of both the D-1 and D-2 antagonist. Duration of DNQX-induced feeding was also attentuated by both dopamine antagonists $[F(2,16)=4.74, p$ $<0.05$ ]. This reduction was not due to general motoric impairment, since the locomotion scores in animals treated with the antagonists were the same or higher than in the control condition, and since latencies to feed were not affected by neuroleptic treatment (see Table 2). For the experiment with neuroleptics, motor activity scores were (total/30 $\mathrm{min}$ ): DNQX-vehicle, $40 \pm$ 10, DNQX-haloperiodol, $75 \pm 26$, DNQX-SCH 23390, $34 \pm$ 11 (no significant difference).

\section{Involvement of the lateral hypothalamus in DNQX-induced feeding}

We noted that the intensity, rapid onset, and general profile of feeding following medial accumbens DNQX infusions bore a striking resemblance to the ingestive behavior observed following electrical stimulation of the lateral hypothalamus (Valenstein, 1969; Wise, 1974; Stellar et al., 1979; Berridge and Valenstein, 1991). Since an extensive lateral hypothalamic projection is one of the major features that distinguishes the shell from the core (Heimer et al., 1991), it was hypothesized that DNQXinduccd feeding was mediatcd via the lateral hypothalamus. In order to test this hypothesis, rats were bilaterally cannulated in two sites, the medial accumbens and lateral hypothalamus. We chose to inactivate lateral hypothalamic neurons with infusions of the $\mathrm{GABA}_{\mathrm{A}}$ agonist muscimol (Krupa et al., 1993). Muscimol causes hyperpolarization of neurons by binding to the GABA receptor and increasing chloride conductance; moreover, there is an abundance of $\mathrm{GABA}_{\mathrm{A}}$ receptors in the hypothalamus (Matsumoto, 1989). All animals received DNQX $(0.75 \mu \mathrm{g})$ infusions into the medial nucleus accumbens in conjunction with three different lateral hypothalamic infusions: 0 (saline), $10 \mathrm{ng}$, and 
$25 \mathrm{ng}$ muscimol (treatments were counterbalanced across test days). Muscimol infused into the lateral hypothalamus just prior to administration of DNQX into the medial accumbens dosedependently attenuated the DNQX fecding response (Fig. 2), with the higher dose completely antagonizing the behavioral response. Analysis of variance indicated that there was an overall treatment effect for food intake $[F(2,10)=14.2, p<0.001]$; DNQX-induced intake was reduced by both doses of muscimol. Feeding duration was also decreased by concurrent injection of mescimol $[F(2,10)=6.7, p<0.01)$, with the higher dose significantly reducing feeding duration. It is unlikely that general motor inhibition was responsible for the blockade of feeding, since the locomotor scores for the muscimol conditions during the first $10 \mathrm{~min}$ were not significantly different from those following the saline-lateral hypothalamus condition, and muscimoltreated animals sniffed and made contact with the food but did not consume it. The locomotor score for the first $10 \mathrm{~min}$ for the DNQX/25 ng muscimol treatment group was $4 \pm 2$; for the DNQX/vehicle treatment group it was $10 \pm 3$ (no significant difference).

\section{Histology}

Representative examples of histological analysis are shown in Figure 3. Although there was some normal surgical variation in the placements of the injection cannulae within the accumbens, particularly in the anterior-posterior plane, injection sites were consistently in the desired central or medial accumbens regions. Also shown in Figure 3 is an example of lateral hypothalamic placements. Figure 4 shows histology from one animal in the unilateral angled cannula experiment.

\section{Discussion}

The present findings provide evidence that the core and shell subregions of the nucleus accumbens may have fundamentally different behavioral roles, particularly with regard to the glutamatergic input. A pronounced feeding response was observed following blockade of non-NMDA receptors in the medial shell region of the nucleus accumbens. This response was pharmacologically selective; infusion of NMDA antagonists did not affect ingestive behavior, suggesting that AMPA and/or kainate receptors in the shell region may play a unique role in the control of feeding behavior. Moreover, the response was found to be remarkably anatomically specific, in that infusions of DNQX into the core, just $0.8 \mathrm{~mm}$ lateral to the shell, did not produce feeding. These findings, together with the evidence for involvement of the lateral hypothalamus, suggest an important role for the medial aspects of accumbens in motivated behavior.

In recent years, much attention has been given to the notion of parallel, functionally segregated circuits linking cortex, basal ganglia, and thalamus (Alexander and Crutcher, 1990). The pattern of connectivity between these structures, as well as behavioral and electrophysiological data, suggests that the functional specialization that occurs in cortex is conserved within multiple output structures. This notion has been further refined by evidence that within the "limbic" circuit there is additional functional specificity, reflected in the histochemically distinct core and shell subterritories of the nucleus accumbens, as well as in quite distinct differences in their afferent and efferent connectivity (Alheid and Heimcr, 1988; Zahm and Brog, 1992; Deutch et al., 1993). The core region of accumbens has direct access to motor output systems by virtue of its close connections to basal ganglia pathways, and is postulated to influence voluntary motor activity. The shell region, in contrast, is traversed by neural pathways closely associated with affective processing and regulation of viscero-endocrine responses. For example, in addition to reciprocal connections with the lateral hypothalamus, the shell receives input from brainstem autonomic centers such as the parabrachial nucleus and nucleus of the solitary tract, both directly and via projections from aganular insular ("visceral") cortex (Brog et al., 1993). Although the vast majority of behavioral studies of the nucleus accumbens have considered it as a homogenous structure, several recent investigations that have specifically examined core-shell differences support the suggestion of a dichotomous nature. A recent study reported that blockade of NMDA receptors in the core, but not the shell, reduces cocaine-elicited motor activity (Pulvirenti et al., 1994). Blockade of NMDA receptors in the core, but not the shell, reduces motor activity in an open field, exploration of novel objects, noveltyelicited locomotion, and disrupts spatial learning and performance in a foraging task (Maldonado-Irizarry and Kelley, 1994, 1995), suggesting that the core is relatively more involved in locomotor functions than the shell. Although little work has been aimed at ascertaining the functions of the shell region of accumbens, evidence that it processes affective information is provided by the finding that the shell region, compared with the core, is particularly susceptible to activation by stress (Deutch and Cameron, 1992). That finding, together with the present results, suggests that the accumbens shell subterritory plays a role in both appetitive and aversive motivation.

The feeding response described here was completely abolished by concurrent inactivation of the lateral hypothalamus. Both the nucleus accumbens and lateral hypothalamus have long been considered to play a critical role in brain mechanisms of reinforcement and goal-directed behaviors. The nucleus accumbens is thought to play a key role in the facilitation of behavioral responses to natural and conditioned incentive stimuli; drugs that artificially activate this system, such as cocaine, produce intense euphoriant effects (Wise and Bozarth, 1987). Electrical stimulation of the lateral hypothalamus results in evoked goal-directed behaviors such as eating, drinking, locomotion, and sexual behavior, that is, behaviors critical for biological adaptation and survival (Valenstein, 1969; Devor et al., 1970; Wise, 1974; Hoebel, 1975). Damage to lateral hypothalamic neurons results in profound disruption of ingestive behaviors in the absence of motor deficits (Dunnett et al., 1985; Winn et al., 1990); ncurons responsive to reward and stimuli associated with reward are present in both the accumbens and lateral hypothalamus (Ono et al., 1981; Rolls, 1984). The present findings demonstrate a functional link between these two brain regions, and suggest that the shell subregion, in particular, exerts an important modulating influence on lateral hypothalamic neurons. Although direct reciprocal connections between the medial nucleus accumbens and lateral hypothalamus have been described previously (Zahm and Brog, 1992), until now there has been little information about the behavioral correlates of this connection.

A tentative model regarding the mechanisms underlying the feeding response is diagrammed in Figure 5. Certain neural inputs may normally exert a tonic excitatory effect on shell neurons, via non-NMDA (most likely AMPA and/or kainate) receptors. Temporary removal of this excitation with DNQX causes shell-hypothalamic neurons to become inactive, thereby disinhibiting intrinsic lateral hypothalamic neurons. This disinhibition resembles electrical stimulation and causes the animals to eat. A basic assumption of the model is that neurons arising in the 


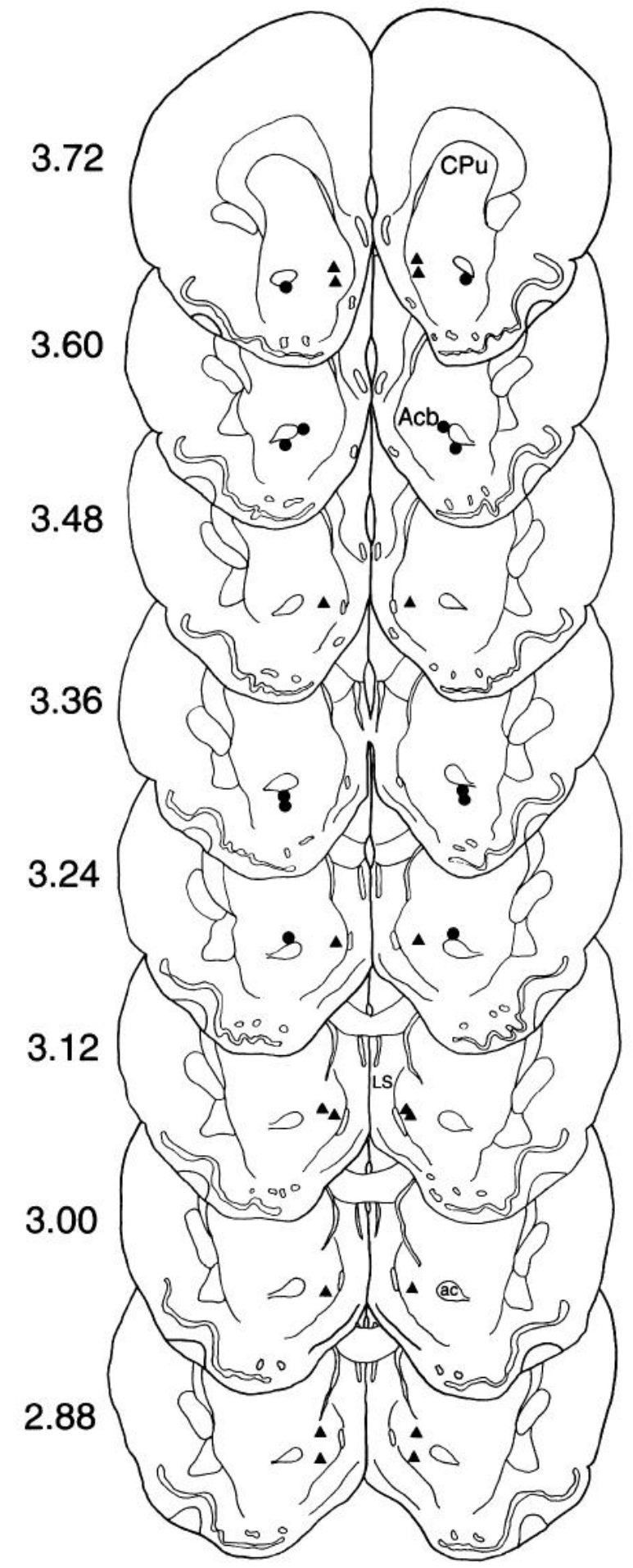

A

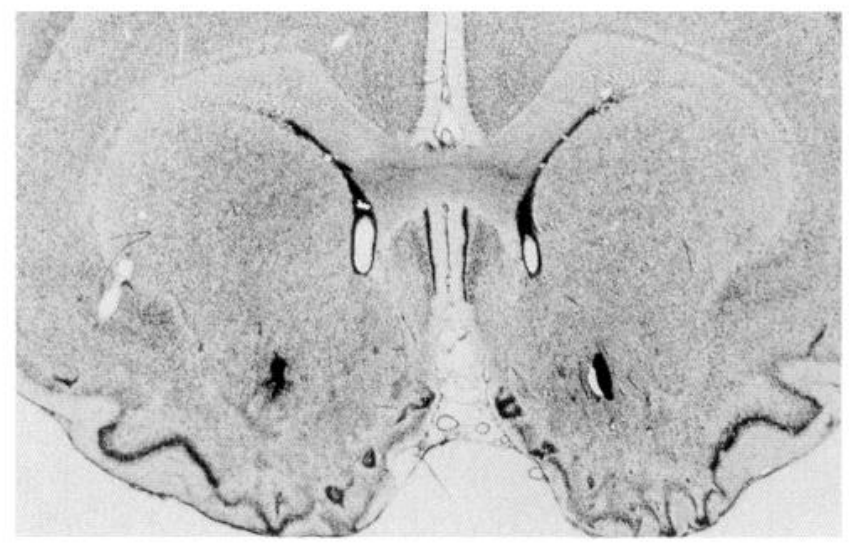

B

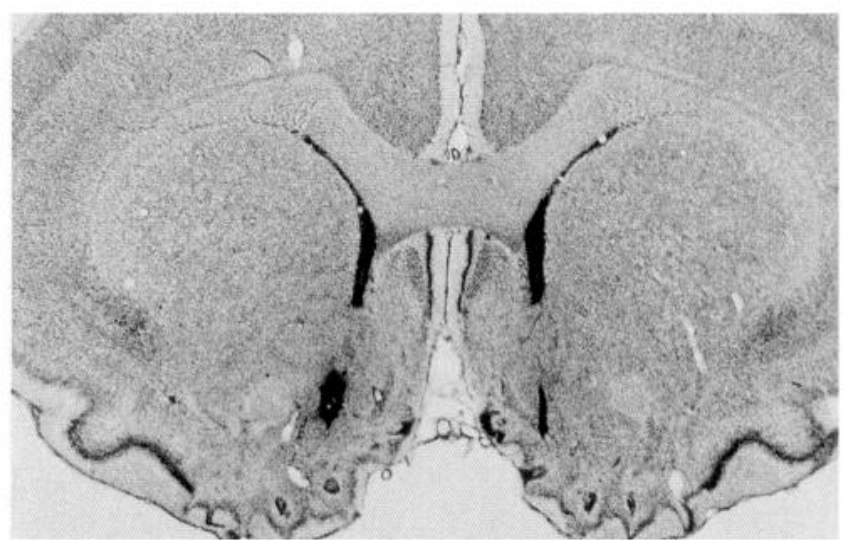

C

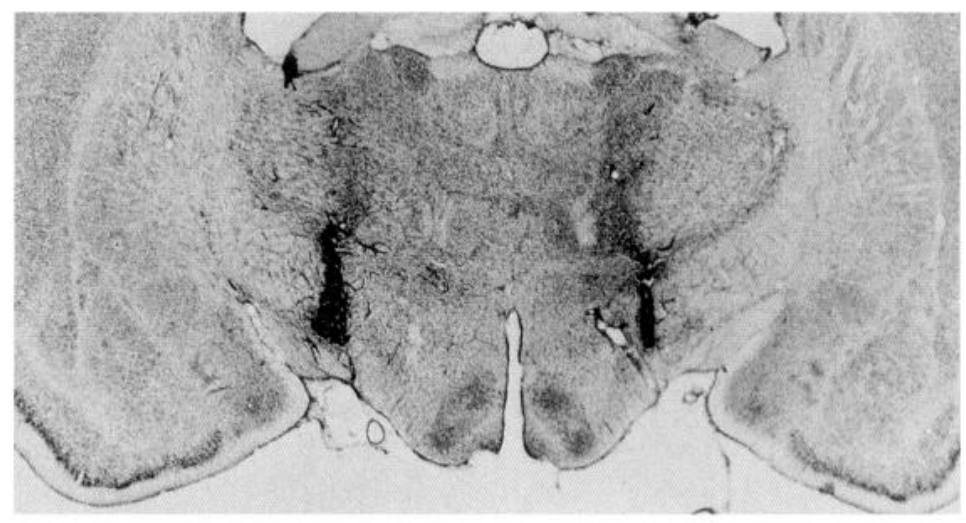

Figure 3. Representative reconstructions of serial coronal sections (from the animals in the DNQX experiment, for which data is shown in Fig. 1) provided on left side of figure. Drawings were made from a hand-drawn atlas derived from serial coronal sections of a normal rat brain (head orientation: nose bar $5 \mathrm{~mm}$ above interaural zero). Each pair of symbols indicates the approximate location of the bilateral injection site in each animal. Dots represent central accumbens (core) placements; triangles represent medial accumbens (medial shell) placements. Numbers to the left of drawings indicate $\mathrm{mm}$ from bregma. Photomicrographs of Nissl-stained sections on the right show representative cannula tracks for the medial accumbens $(A)$, central accumbens $(B)$, and lateral hypothalamus $(C)$. Abbreviations: $C P u$, caudate-putamen; $A c b$, accumbens; $L S$, lateral septum; ac, anterior commissure.

shell exert an inhibitory influence on lateral hypothalamic neurons, via a GABAergic mechanism. Evidence for an inhibitory pathway from medial accumbens to lateral hypothalamus has been demonstrated (Mogenson et al., 1983). Although the neu- rotransmitter content of this pathway has not yet been identified, most other identified basal ganglia outputs inhibit their target structures via a GABAergic mechanism, including fibers projecting to the ventral tegmental area originating in the shell 
Figure 4. Photomicrograph of cannula track placement in the unilateral, angled control experiment. It can be observed that the track from the guide and injector does not penetrate the ventricle. This rat consumed $4 \mathrm{gm}$ in 30 min (feeding duration was $448 \mathrm{sec}$ ) following infusion of $0.75 \mu \mathrm{g}$ of DNQX.

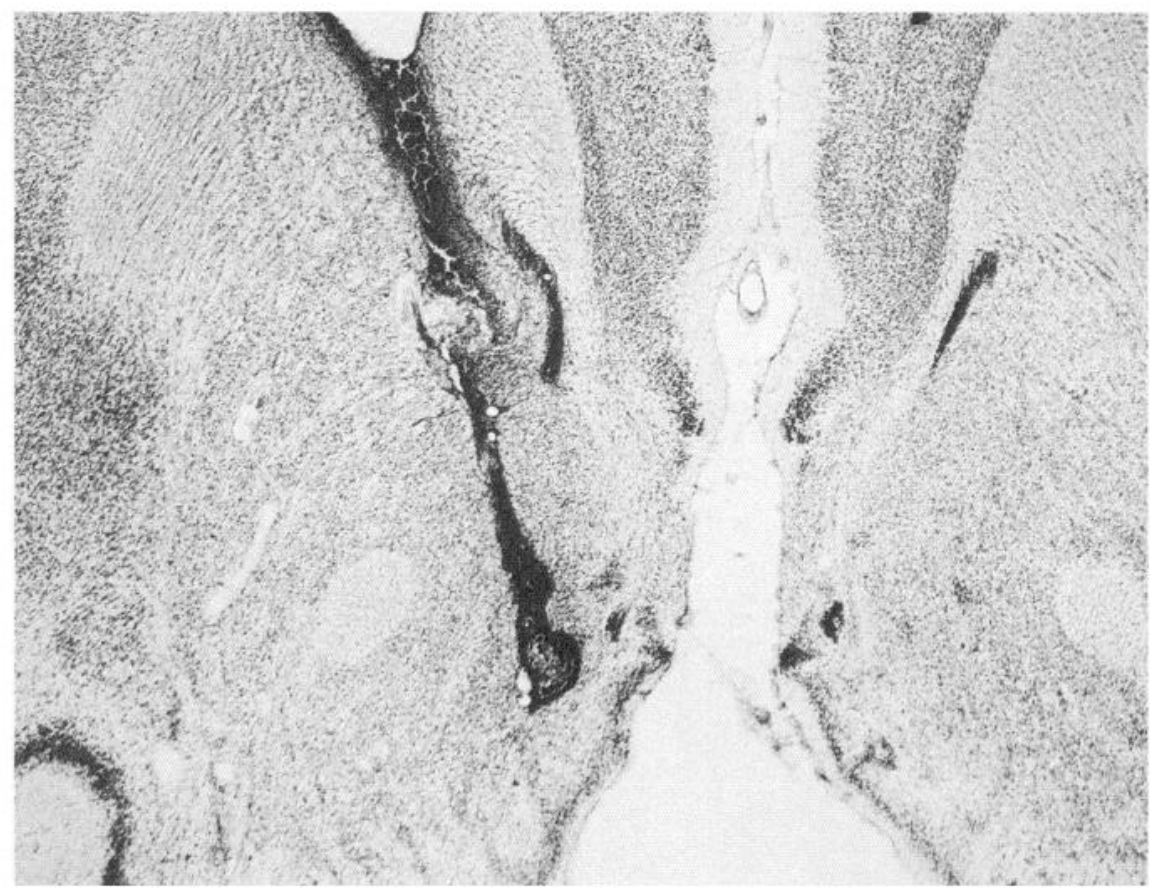

(Chevalier and Deniau, 1987; Kalivas et al., 1993). Moreover, there is substantial evidence that GABA receptors in the hypothalamus are involved in regulation of feeding (Matsumoto, 1989). GABA or $\mathrm{GABA}_{\mathrm{A}}$ agonists infused into the lateral hypothamus decrease feeding, while infusion of the $\mathrm{GABA}_{\mathrm{A}}$ an-

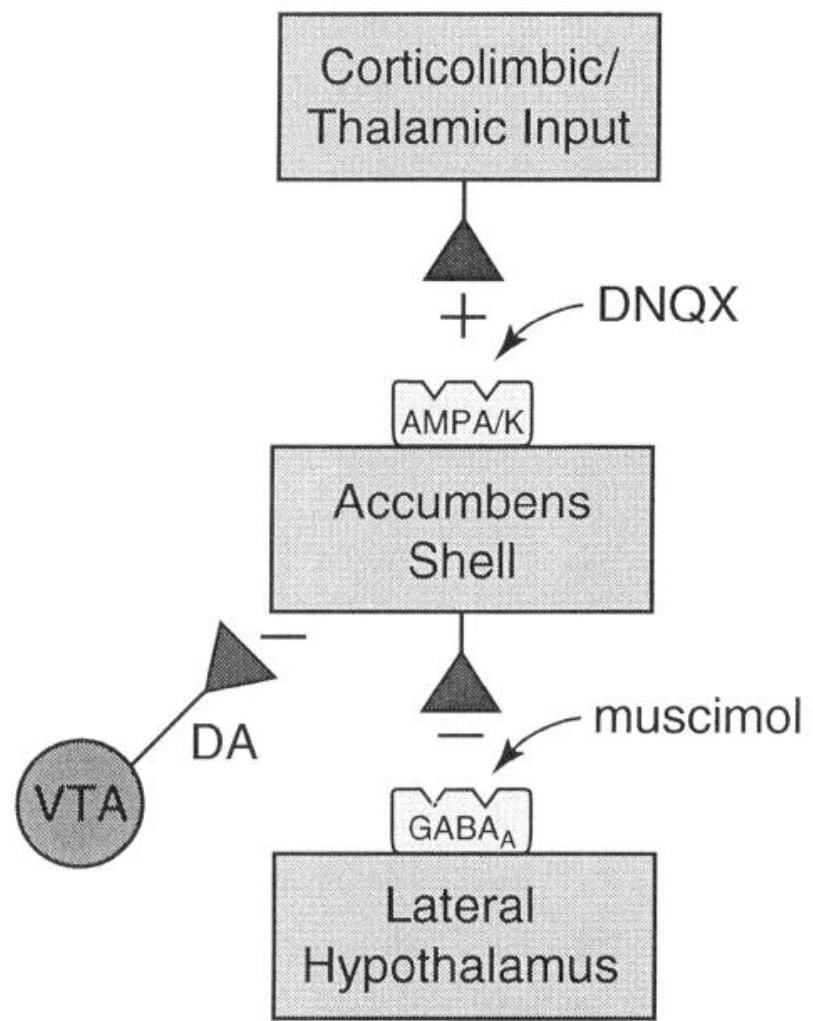

Figure 5. Schematic illustration of hypothesized mechanisms underlying DNQX-induced feeding, as described in Discussion. Abbreviations: VTA, ventral tegmental area; $D A$, dopamine; $A M P A / K$, AMPA and kainate receptors. For other abbreviations, see text. tagonists bicuculline or picrotoxin increases this behavior (Kelly et al., 1977, 1979; Tsujii and Bray, 1991). Excitation of lateral hypothalamic neurons with infusion of excitatory amino acids results in a rapid-onset, intense feeding response that appears highly localized to this particular hypothalamic site (Stanley et al., 1993).

The results with dopamine antagonists suggest that dopamine may play a modulatory role in DNQX-elicited feeding. Both the D-1 and D-2 antagonists reduced DNQX-induced feeding by about half. This result is in accordance with the theory that dopamine is a critical modulator of the behavioral effects evoked by electrical stimulation of the lateral hypothalamus. Feeding evoked by lateral hypothalamic electrical stimulation is reduced by neuroleptic treatment, and lateral hypothalamic stimulation is associated with increased release of dopamine in the nucleus accumbens (Phillips and Nikaido, 1975; Mogenson and Wu, 1982; Hernandez and Hoebel, 1988). Feeding can also be elicited with low doses of amphetamine injected into the nucleus accumbens (Evans and Vaccarino, 1986). Further, the rewarding effects of lateral hypothalamus stimulation are dependent on intact forebrain dopamine systems (Wise and Rompré, 1989).

Electrophysiological experiments further support the model noted above. Intracellular recordings from medial accumbens output neurons, during stimulation of corticolimbic inputs, results in excitatory responses that are depressed by application of dopamine (Pennartz et al., 1992, 1993). In a related study, the postsynaptic response of accumbens output neurons was found to be primarily mediated by quisqualate/kainate receptors, while the contribution of NMDA receptors was very small (Pennartz et al., 1991). These findings support the hypothesis that corticolimbic (or thalamic) inputs normally exert a tonic excitatory influence on accumbens shell efferent neurons. When this influence is attenuated either via application of a non-NMDA antagonist or activation of dopamine, appetitive behavior is facilitated. Moreover, the present findings may explain why animals show oral motor behaviors, such as chewing, when this 
region is stimulated with a dopaminergic agonist (Prinssen et al., 1994).

In summary, the present experimental findings suggest that the accumbens shell subterritory is part of a functionally specialized circuit mediating motivational processes. It should be noted that much further work is needed to adequately characterize the role of the shell, its inputs and outputs, and various neurotransmitter interactions within this area in the control of ingestive behavior. For example, the model described above assumes that certain EAA-coded inputs exert a tonic excitatory influence on shell neurons, but the source of this influence remains an open question. Similarly, although dopamine in the accumbens has been linked to modulation of feeding, there has been little investigation of core-shell differences in the response to dopaminergic stimulation, nor of the role of different DA receptor subtypes in these subregions. Finally, knowledge of the precise borders of the zone sensitive to EAA antagonists remains to be elucidated, as well as whether other output areas, such as ventral pallidum and ventral tegmental area, may also play a role.

\section{References}

Albin RL, Makowiec RL, Hollingsworth ZR, Dure LS, Penney JB Young AB (1992) Excitatory amino acid binding sites in the basal ganglia of the rat: a quantitative autoradiographic study. Neuroscience 46:35-48.

Alexander GE, Crutcher D (1990) Functional architecture of basal ganglia circuits: neural substrates of parallel processing. Trends Neurosci 13:266-271.

Alheid GF, Heimer L (1988) New perspectives in basal forebrain organization of special relevance for neuropsychiatric disorders: the striatopallidal amygdaloid and corticopetal components of substantia innominata. Neuroscience 27:1-39.

Beninger RJ (1983) The role of dopamine in locomotor activity and learning. Brain Res Rev 6:173-196.

Berridge KC, Valenstein ES (1991) What psychological process mediates feeding evoked by electrical stimulation of the lateral hypothalamus? Behav Neurosci 105:3-14.

Brog JS, Salyapongse A, Deutch AY, Zahm DS (1993) The patterns of afferent innervation of the core and shell in the "accumbens" part of the rat ventral striatum: immunohistochemical detection of retrogradely transported fluoro-gold. J Comp Neurol 338:255-278.

Chevalier G, Deniau JM (1987) Functional significance of a double GABAergic inhibitory link in the striato-nigro-fugal pathways. In: Neurotransmitter interactions in the basal ganglia (Sandler M, Feuerstein C, Scatton B, eds), pp 83-94. New York: Raven.

Cooper SJ, Kirkham TC (1993) Opioid mechanisms in the control of food consumption and taste preferences. In: Handbook of experimental pharmacology (Herz A, ed), pp 239-262. Berlin: Springer.

Deutch AY, Cameron DS Pharmacological characterization of dopamine system in the nucleus accumbens core and shell. Neuroscience 46:49-56.

Deutch AY, Bourdelais AJ, Zahm DS (1993) The nucleus accumbens core and shell: accumbal compartments and their functional attributes. In: Limbic motor circuits and neuropsychiatry (Kaliva PW, Barnes CD, eds), pp 45-88. Boca Raton, FL: CRC.

Devor MG, Wise RA, Milgram NW, Hoebel BG (1970) Physiological control of hypothalamically elicited feeding and drinking. J Comp Physiol Psychol 73:226-232.

Dunnett SB, Lane DM, Winn P (1985) Ibotenic acid lesions of the lateral hypothalamus: comparison with 6-hydroxydopamine-induced sensorimotor deficits. Neuroscience 14:509-518.

Evans KR, Vaccarino FJ (1986) Intra-nucleus accumbens amphetamine: dose-dependent effects on food intake. Pharmacol Biochem Behav 25:1149-1151.

Fibiger HC, Phillips AG (1986) Reward, motivation and cognition: psychobiology of mesotelencephalic dopamine systems. In: Handbook of physiology: the nervous system, Vol 4 (Mountcastle VB, Bloom FE, Geiger SR, eds), pp 647-675. Bethesda MD: American Physiological Socicty.

Fuller TA, Russchen FT, Price JL (1987) Sources of presumptive glu- tamatergic/aspartergic afferents to the not ventral striatopallidal region. J Comp Ncurol 258:317-338.

Groenewegen HJ, Russchen FT (1984) Organization of the efferent projections of the nucleus accumbens to pallidal, hypothalamic, and mesencephalic structures: a tracing and immunohistochemical study in the cat. J Comp Neurol 223:347-367.

Groenewegen HJ, Becker NEHM, Lohman AHM (1980) Subcortical afferents of the nucleus accumbens septi in the cat, studied with retrograde axonal transport of horseradish peroxidase and bisbezimid. Neuroscience 7:977-996.

Heimer L, Wilson RD (1975) The subcortical projections of the allocortex: similarities in the neural associations of the hippocampus, the piriform cortex and the neocortex. In: Golgi centennial symposium (Santini M, ed), pp 177-193. New York: Raven.

Heimer L, Zahm DS, Churchill L, Kalivas PW, Wohltmann C (1991) Specificity in the projection patterns of accumbal core and shell in the rat. Neuroscience 41:89-125.

Hernandez L, Hoebel BG (1988) Food reward and cocaine increase extracellular dopamine in the nucleus accumbens as measured by microdialysis. Life Sci 42:1705-1712.

Hoebel BG (1975) Brain-stimulation reward and aversion in relation to behavior. In: Brain stimulation reward (Wauquier A, Rolls ET, eds), pp 335-372. Amsterdam: North Holland.

Kelley AE, Domesick VB, Nauta WJH (1982) The amygdalostriatal projection in the rat-an anatomical study by anterograde and retrograde tracing methods. Neuroscience 7:615-630.

Kelly J, Alheid GF, Newberg A, Grossman SP (1977) GABA stimulation and blockade in the hypothalamus and midbrain: effects on feeding and locomotor activity. Pharmacol Biochem Behav 7:537541.

Koob GF, Bloom FE (1988) Cellular and molecular mechanisms of drug dependence. Science 242:715-723.

Krupa DJ, Thompson JK, Thompson RF (1993) Localization of a memory trace in the mammalian brain. Science 260:989-991.

Maldonado-Irizarry CS, Kelley AE (1994) Differential behavioral effects following microinjection of an NMDA antagonist into nucleus accumbens subregions. Psychopharmacology 116:65-72.

Maldonado-Irizarry CS, Kelley $\Lambda E$ (1995) Excitatory amino acid receptors within nucleus accumbens subregions differentially mediate spatial learning in the rat. Behav Pharmacol, in press.

Mansour A, Khachaturian H, Lewis ME, Akil H, Watson SJ (1987) Autoradiographic differentiation of mu, delta, and kappa opioid receptors in the rat forebrain and midbrain. J Neurosci 7:2445-2464.

Matsumoto RR (1989) GABA receptors: are cellular differences reflected in function? Brain Res Rev 14:203-225.

McGeer PL, McGeer EG, Scherer U, Singh KA (1977) A glutamatergic corticostriatal path? Brain Res 128:369-373.

Mogenson GJ, Wu M (1982) Neuropharmacological and electrophysiological evidence implicating the mesolimbic dopamine system in feeding responses elicited by electrical stimulation of the medial forebrain bundle. Brain Res 253:243-251.

Mogenson GJ, Jones DL, Yim CY (1980) From motivation to action: functional interface between the limbic system and the motor system. Prog Neurobiol 14:69-97.

Mogenson GJ, Swanson LW, Wu M (1983) Neural projections from nucleus accumbens to globus pallidus substantia innominata and lateral preoptic-lateral hypothalamic area: an anatomical and electrophysiological investigation in the rat. J Neurosci 3:189-202.

Ono T, Sasaki H, Fukuda M, Muramoto K (1981) Monkey lateral hypothalamic neuron response to sight of food and during bar press and ingestion. Neurosci Lett:21:99-104.

Pennartz CMA, Boeijinga PH, Kitai ST, Lopes da Silva FH (1991) Contribution of NMDA receptors to postsynaptic potentials and paired-pulse facilitation in identified neurons of the rat nucleus accumbens in vitro. Exp Brain Res 86:190-198.

Pennartz CMA, Dolleman-Van der Weel MJ, Kitai ST, Lopes da Silva FH (1992) Presynaptic dopamine D1 receptors attenuate excitatory and inhibitory limbic inputs to the shell region of the rat nucleus accumbens studied in vitro. J Neurophysiol 67:1325-1334.

Pennartz CMA, Ameerun RF, Groenewegen HJ, Lopes da Silva FH (1993) Synaptic plasticity in an in vitro slice preparation of the rat nucleus accumbens. Eur J Neurosci 5:107-117.

Phillips AG, Nikaido RS (1975) Disruption of brain stimulation-induced feeding by dopamine receptor blockade. Nature 258:750 751 . Prinssen EPM, Balestra W, Bemelmans FFJ, Cools AR (1994) Evi- 
dence for a role of the shell of the nucleus accumbens in oral behavior of freely moving rats. J Neurosci 14:1555-1562.

Robbins TW, Cador M, Taylor JR, Everitt BJ (1989) Limbic-striatal interactions in reward-related processes. Neurosci Biobehav Rev 13: $155-162$.

Roberts DCS, Koob GF, Klonoff P, Fibiger HC (1980) Extinction and recovery of cocaine self-administration following 6-hydroxydopamine lesions of the nucleus accumbens. Pharmacol Biochem Behav 12:781-787.

Robinson TG, Beart PM (1988) Excitant amino acid projections from rat amygdala and thalamus to nucleus accumbens. Brain Res Bull 20: 467-471.

Rolls ET (1984) The neurophysiology of feeding. Int J Obesity 8:139150.

Stanley BG, Willet VL III, Donias HW, Ha LH, Spears LC (1993) The lateral hypothalamus: primary site mediating excitatory amino acidelicited feeding. Brain Res 630:41-49.

Stellar JR, Brooks FH, Mills LE (1979) Approach and withdrawal analysis of the effects of hypothalamic stimulation and lesions in rats. J Comp Physiol Psychol 93:446-466.

Tallaksen-Green SJ, Wiley RG, Albin RL (1992) Localization of striatal excitatory amino acid binding site subtypes to striatonigral projection neurons. Brain Res 594:165-170.

Tsujii S, Bray GA (1991) GABA-related feeding control in genetically obese rats. Brain Res 540:48-54.
Valenstein ES (1969) Behavior elicited by hypothalamic stimulation: a prepotency hypothesis. Brain Behav Evol 2:295-316.

Walaas I, Fonnum F (1979) The effects of surgical and chemical lesions on neurotransmitter candidates in the nucleus accumbens. Neuroscience 4:209-216.

Weiss F, Hurd YL, Ungerstedt U, Markou A, Plotsky PM, Koob GF (1993) Neurochemical correlates of cocaine and ethanol self-administration. Ann NY Acad Sci 654:220-241.

Winn P, Clark A, Hastings M, Latimer M, Rugg E, Brownlee B (1990) Excitotoxic lesions of the lateral hypothalamus made by $N$-methyl D-aspartate in the rat: behavioural, histological, and biochemical analyses. Exp Brain Res 82:628-636.

Wise RA (1974) Lateral hypothalamic electrical stimulation: does it make animals "hungry"? Brain Res 67:187-209.

Wise RA, Bozarth MA (1987) A psychostimulant theory of addiction. Psychol Rev 94:469-492.

Wise RA, Rompré PP (1989) Brain dopamine and reward. Annu Rev Psychol 40:191-225.

Zahm DS, Brog JS (1992) On the significance of subterritories in the "accumbens" part of the rat ventral striatum. Neuroscience 50:751767.

Zahm DS, Heimer L (1993) Specificity in the efferent projections of the nucleus accumbens in the rat: comparison of the rostral pole projection patterns with those of the core and shell. J Comp Neurol 327: 220-232. 